\title{
MANDADO DE SEGURANÇA CONTRA ATO DE TRIBUNAL REGIONAL ELEITORAL
}

\author{
Writ of Mandamus Against Regional Electoral Court Act
}

Tarcisio Vieira de Carvalho Neto

Resumo: A ação constitucional do mandado de segurança é amplamente conhecida pelo seu rito célere voltado à obtenção do resultado pretendido. Isso talvez possa explicar por que o mandado de segurança é amplamente utilizado em controvérsias de natureza eleitoral, considerada a urgência inerente a tais demandas. Tendo em vista sua ampla utilização, à luz do entendimento do TSE e do STF acerca da matéria, bem como das hodiernas reviravoltas no tema, mostra-se imprescindível o estudo detido do cabimento e, em especial, da competência para julgamento do mandado de segurança contra ato de tribunal regional, em prol de uma solução efetiva e, por isso, necessariamente célere.

Palavras-chave: Mandado de segurança. Eleitoral. Tribunal regional. Competência.

\begin{abstract}
The constitutional action of a writ of mandamus is widely known for being a quick path to achieve the intended result. This might explain why writs of mandamus are widely used in electoral controversies, considering their time-sensitive nature. Given the widespread use of such an instrument, observing the precedents of the Brazilian Supreme Electoral Court and Supreme Court, and being aware of the current twists and turns in the theme, it is crucial to thoroughly explore its applicability and, in particular, which court is competent to judge a writ of mandamus against acts of an electoral court of appeals. Such careful analysis contributes to addressing the issue effectively and with agility.
\end{abstract}

Keywords: Writ of mandamus. Electoral. Second-instance electoral court. Competence.

Artigo recebido em 19 jul. 2021

Editor responsável: Luiz Magno Pinto Bastos Junior

DOI: https://doi.org/10.53323/resenhaeleitoral.v25i1.141 


\section{Introdução}

O mandado de segurança é, de longa data, conhecido como garantia constitucional, com natureza jurídica de ação, voltado a tutelar direito líquido e certo, entendido como aquele que prescinde de dilação probatória, não amparado por habeas corpus ou habeas data, sempre que o responsável por ilegalidade ou abuso de poder for autoridade pública ou agente de pessoa jurídica no exercício de atribuições do poder público.

$\mathrm{Na}$ seara eleitoral, o writ of mandamus encontra algumas especificidades dignas de nota, advindas, em especial, da superlativa demanda de celeridade afeta aos processos em trâmite perante a justiça especializada.

Conhecido, portanto, como uma das formas processuais mais perfeitas e acabadas, dentre os instrumentos jurídicos mais eficazes contra os exageros administrativos, encontra o mandado de segurança um ambiente profícuo diante da dinâmica necessariamente célere dos pleitos.

Há, na prática, uma variedade temática considerável no manejo do mandado de segurança perante a Justiça Eleitoral, tanto em âmbito administrativo quanto jurisdicional. Temas bastante corriqueiros envolvem impetrações contra atos praticados por presidente de comissão de partidos políticos ${ }^{1}$ ou mesmo de diretórios partidários ${ }^{2}$, contra decisões envolvendo servidores públicos da Justiça Eleitoral ${ }^{3}$, atinente à quebra de sigilo de dados eletrônicos em investigação criminal ${ }^{4}$, inscrição relativa ao cometimento de ilícito no cadastro eleitoral ${ }^{5}$, dentre outros. A respeito do tema, confira-se:

$\mathrm{Na}$ seara eleitoral, o Mandado de Segurança encontra amplo campo de atuação, sem apresentar limitação, em ano macroeleitoral ou microeleitoral, desde que haja a configuração de direito líquido e certo. Ele tem cabimento em qualquer fase do processo, seja preparatória, votação, apuração e diplomação (VELLOSO; AGRA, 2014, p. 428).

Com esse cenário em mente, aliando a celeridade nata do mandado de segurança à dinâmica igualmente precípete das eleições, deve-se

\footnotetext{
${ }^{1}$ AgR-MS no 0601345-45/ES, Rel. Min. Luis Felipe Salomão, DJe de 22/04/2021.

${ }^{2}$ AgR-REspe no 0600248-42/CE, Rel. Min. Sergio Silveira Banhos, PSESS de 04/12/2020.

${ }^{3}$ AgR-MS nº 0600072-19/RO, Rel. Min. Mauro Campbell Marques, DJe de 06/04/2021.

${ }^{4}$ RMS nº 0603474-42/GO, Rel. Min. Tarcisio Vieira de Carvalho Neto, DJe de 12/08/2020.

${ }^{5}$ AgR-MS no 0601423-39/MT, Rel. Min. Mauro Campbell Marques, DJe de 30/11/2020.
} 
considerar outro elemento para que se possa encontrar um nicho absolutamente pertinente e delicado no estudo do mandado de segurança: a faceta administrativo-eleitoral, desempenhada das mais variadas formas no âmbito de todas as instâncias da justiça especializada.

Detém a Justiça Eleitoral várias funções, quais sejam: a administrativa, a jurisdicional, a normativa e a consultiva. No âmbito administrativo, prepara, organiza e executa todo o processo eleitoral, tornando inaplicáveis alguns preceitos básicos próprios da jurisdição comum, como o princípio da demanda, ou da não atuação de ofício. Na doutrina, é notado esse contexto único que implica à seara eleitoral a saída "do seu leito natural”, como bem aponta José Jairo Gomes (2016, p. 80).

Essa particularidade demanda uma análise igualmente específica na comparação tanto do cabimento quanto da competência para julgamento de mandado de segurança na justiça especializada, quando em contraponto à doutrina estabelecida na jurisdição comum, cristalizada, inclusive, em súmulas no $\mathrm{STJ}^{6}$ e no $\mathrm{STF}^{7}$. É de se destacar trecho doutrinário que bem aquilata essa singularidade:

O cabimento do mandado de segurança contra ato judicial assume destaque e importância no direito processual eleitoral, não só por causa da irrecorribilidade das decisões interlocutórias - tal como se passa no processo do trabalho e nos juizados especiais. É que, além dessa circunstância, na Justiça Eleitoral as decisões são mais céleres e o sistema processual é extremamente baralhado, circunstâncias que fazem surgir inúmeras dificuldades na identificação do meio processual adequado para a tutela de seus direitos - em especial aquele destinado à impugnação das decisões judiciais. Lembre-se, ainda, que a acentuada competência atribuída à Justiça Eleitoral faz com que o intérprete se defronte com provimentos em que existe enorme dificuldade para a sua compreensão como sendo um ato administrativo, judicial ou jurisdicional. Em arremate, o direito processual eleitoral tem uma característica única - inexistente em qualquer outro sistema processual -, a saber, a existência de datas limites para o julgamento das causas e para a prática de atos no âmbito da própria Justiça

${ }^{6}$ Súmula n⿳0 41/STJ: O Superior Tribunal de Justiça não tem competência para processar e julgar, originariamente, mandado de segurança contra ato de outros Tribunais ou dos respectivos órgãos.

${ }^{7}$ Súmula no 624/STF: Não compete ao Supremo Tribunal Federal conhecer originariamente de mandado de segurança contra atos de outros tribunais. 
Eleitoral - isto é, a celeridade processual é marcada por fatores temporais. Tudo isso faz com que todo o processo seja naturalmente urgente e premente, sendo certo que as decisões judiciais devem ser eficazes e capazes de imediatamente produzir efeitos, repercutindo de forma concreta no âmbito da sociedade (JORGE; LIBERATO; RODRIGUES, 2016, p. 687).

Nessa linha, a necessidade de estudo envolvendo o controle jurisdicional eficaz da própria administração eleitoral, imbuída do apuro próprio dos pleitos, torna fundamental perquirir o cabimento e o órgão competente para a análise de writs impetrados dentro da estrutura da Justiça Eleitoral.

\section{Objetivo}

Dentre tantas funções anômalas próprias da Justiça Eleitoral quando comparadas com a justiça comum, podem-se elencar a inscrição de eleitores, a transferência de domicílio eleitoral, a designação de locais de votação, a expedição de títulos eleitorais, e outras atividades características que podem descambar para a abusividade ou a ilegalidade, de maneira que o controle jurisdicional de tais atos é fundamental.

A eficiência do controle é inerente à celeridade de sua realização, bem como à autoridade competente para tanto. Com esse enfoque, é importante delimitar o cenário da compreensão da Corte Superior Eleitoral e a atual possível mudança no curso dessa história.

O objetivo central do artigo, portanto, é buscar o panorama atual e exato do entendimento jurisprudencial no âmbito do TSE acerca do cabimento de mandado de segurança impetrado contra ato de tribunal regional, além da definição sobre a competência para apreciar a ação.

A proposta é lançar sobre esse diagnóstico uma diretriz segura do caminho a ser seguido em prol da estabilização jurisprudencial, bem como da efetividade em termos de controle dos atos administrativo-eleitorais na seara especializada.

\section{Método}

A coleta de dados para o embasamento do estudo foi feita no acervo jurisprudencial do TSE, bem como na análise de precedentes que guiaram o entendimento até então firmado e, como se verá, passível de revisão a partir de alguns posicionamentos conflitantes em voga. 
Há importante alicerce sobre o tema no âmbito do STF, que merece especial relevo, assim como toda a trilha percorrida no TSE a partir de casos concretos, desaguando no atual cenário um tanto quanto tormentoso, ao qual se dará a solução adequada.

Importante destaque no que tange ao método é não apenas a verificação do acervo oficial atinente aos precedentes, mas, em especial, a análise do julgamento de alguns casos concretos que denotam com segurança razoável a posição dos membros acerca da matéria, muito embora o resultado oficial, por questões processuais, indique desfecho diverso.

Esse apanhado analítico é crucial porque dele se extrai a própria existência do problema, que é objeto do estudo, bem como é possível trilhar, a partir do diagnóstico seguro, um rumo à solução do tema, com base nos antecedentes históricos que cunharam o entendimento até então remansoso.

\section{Resultados}

Questão absolutamente interessante no estudo jurisprudencial hodierno do TSE envolve a impetração de mandado de segurança contra ato de tribunal regional eleitoral. O entendimento da Corte acerca da matéria, de longa data, é no sentido de afastar sua competência para apreciação de writ impetrado contra ato de membro da Corte local. Nesse particular, o tema foi, inclusive, sumulado no enunciado $\mathrm{n}^{-} 34$, expresso ao dispor que "não compete ao Tribunal Superior Eleitoral processar e julgar mandado de segurança contra ato de membro de Tribunal Regional Eleitoral".

O entendimento é construído com base no art. 22, I, e, da Lei $\mathrm{n}^{\mathrm{o}}$ 4.737/1965, que estipula a competência do Tribunal Superior para o julgamento de mandado de segurança, em matéria eleitoral, relativo a ato dos tribunais regionais. O Regimento Interno do TSE, em seu art. 8o $\mathrm{m}$, repete a redação, expressa ao elencar o cabimento contra ato dos tribunais regionais. A teleologia, portanto, é a de que as referidas normas tratam de decisões colegiadas, e não individuais de seus membros.

Existe uma miríade de precedentes nessa linha, sendo importante destacar o AgR-MS nº 602-02/ES (Rel. Min. Aldir Passarinho Junior, DJe de 14/09/2011), em que se estabeleceu que não "cabe ao e. TSE julgar, originariamente, mandado de segurança interposto contra ato de Tribunal Regional (Súmulas n 624 STF e 41 do STJ)". 
Anos depois, o TSE debateu a edição da sua atual Súmula no 34 no âmbito do PA no 323-45/DF (Rel. Min. Laurita Vaz, Rel. designado Min. Dias Toffoli, DJe de 24, 27 e 28/06/2016). Na ocasião, a proposta de redação da Ministra Laurita Vaz baseou-se em enunciados do STF e do STJ e contou com a concordância, via voto-vista, do Ministro Dias Toffoli.

Houve o encaminhamento de sugestões elaboradas pelo Grupo Executivo Nacional da Função Eleitoral da Procuradoria-Geral Eleitoral e pela Procuradoria Regional Eleitoral da Bahia. Especificamente quanto à Súmula $n^{\circ} 34$ do TSE, foram apresentadas sugestões de duas redações diferentes:

Sugere as seguintes redações: "Não compete ao Tribunal Superior Eleitoral processar e julgar mandado de segurança contra ato judicial de membro de Tribunal Regional Eleitoral" e "Compete ao Tribunal Superior Eleitoral processar e julgar mandado de segurança contra ato judicial de Tribunal Regional Eleitoral"8.

A conclusão, no entanto, foi pelo não acolhimento, "uma vez que a jurisprudência do TSE é pacífica no sentido de que 'não cabe ao e. TSE julgar, originariamente, mandado de segurança interposto contra ato de Tribunal Regional (Súmulas nº 624 STF e 41 do STJ)' (AgR-MS nº 60.202, Rel. Min. Aldir Passarinho Junior, de 02/06/2011)". Além de tal justificativa, explicitou-se que "a natureza do ato praticado pelo juiz membro do TRE se judicial ou administrativo - não é relevante para fixar a competência do TSE, em se tratando de mandado de segurança originário, tendo em vista o disposto no art. 21, VI, da LC nº 35/1979 (LOMAN)".

Com isso em mente, o entendimento jurisprudencial foi assentado e a compreensão, até então indene de dúvidas, era no sentido do cabimento do writ se o ato questionado fosse oriundo do colegiado do tribunal regional. Rechaçava-se, portanto, a impetração voltada contra ato de membro do tribunal, independentemente da natureza - administrativa ou jurisdicional ${ }^{9}$.

Além da fixação do entendimento positivo no que concerne ao cabimento, estipulou-se que a competência para o julgamento do writ de-

\footnotetext{
${ }^{8}$ PA no 323-45/DF, Rel. Min. Laurita Vaz, Rel. designado Min. Dias Toffoli, DJe de 24, 27 e 28/06/2016. Fl. 60.

9 Nesse sentido: AgR-MS no 0600345-10/RS, Rel. Min. Luis Felipe Salomão, DJe de $23 / 09 / 2020$.
} 
penderia da natureza do ato combatido. Se o ato detiver índole jurisdicional, a ação é dirigida ao próprio tribunal regional. Some-se a esse tópico a necessidade de que se esteja diante de decisão judicial irrecorrível e teratológica, na linha do que dispõe a Súmula no 22 do TSE, é dizer, se o ato judicial for recorrível ou sobre ele não pairar a pecha de teratologia ou manifesta ilegalidade, nem sequer o cabimento é aceito.

Tive a oportunidade de decidir nesse sentido em situação na qual a impetração foi voltada contra ato de próprio ministro do TSE que havia concedido efeito suspensivo a agravo interno em recurso especial eleitoral. $\mathrm{O}$ intento do impetrante era, portanto, obter um provimento de contracautela mandamental que sustasse os efeitos da liminar concedida no outro feito. No caso, monocraticamente, neguei seguimento ao mandado de segurança, justamente por estar amparado pela redação da Súmula no 22 do TSE. Em agravo interno, reforcei que o regular exercício do poder geral de cautela pelo relator do feito não poderia ser inquinado de ilegal e, muito menos, teratológico ${ }^{10}$.

Por outro lado, em se tratando de atos de natureza administrativa, uma bifurcação jurisprudencial se fez necessária: contra atos puramente administrativos, cabe mandado de segurança a ser impetrado no próprio tribunal regional ${ }^{11}$; contra atos administrativo-eleitorais, a competência para julgamento do writ permanece no $\mathrm{TSE}^{12}$.

Não obstante tal cenário, o debate foi reavivado no MS $\mathrm{n}^{\circ}$ 0601612-17/PE (Rel. Min. Tarcisio Vieira de Carvalho Neto, Rel. para o acórdão Min. Alexandre de Moraes, julgado em 03/11/2020). O caso envolveu impetração de candidato ao cargo de prefeito do Município de Catende/PE contra ato do Tribunal Regional Eleitoral de Pernambuco (TRE/ PE), consubstanciado na edição de resolução que proibiu, no estado, para as Eleições 2020, a realização de atos presenciais de campanha eleitoral causadores de aglomeração.

Deferi monocraticamente a liminar apenas para determinar ao TRE/PE que procedesse a uma periódica reavaliação do quadro que embasou a edição da combatida resolução, instando a autoridade sanitária estadual a se manifestar de forma dinâmica sobre a ratificação ou não do parecer por ela anteriormente formalizado. Na sequência, encaminhei a decisão precária para referendo do Plenário, momento em que se instaurou debate verticalizado acerca da competência.

\footnotetext{
${ }^{10}$ AgR-MS nº 0600418-79/AM, Rel. Min. Tarcisio Vieira de Carvalho Neto, DJe de 10/08/2020.

${ }^{11}$ AgR-MS no 311-90/BA, Rel. Min. Henrique Neves da Silva, DJe de 26/09/2014.

${ }^{12}$ MS nº 0601044-98/MT, Rel. Min. Edson Fachin, DJe de 02/12/2020.
} 
O Ministro Alexandre de Moraes inaugurou a divergência e apontou "a incompetência absoluta do Tribunal Superior Eleitoral para julgamento de mandado de segurança contra ato, mesmo ato colegiado, mas ato administrativo colegiado de tribunais regionais eleitorais". Apesar da menção à incompetência envolvendo apreciação de mandado de segurança contra atos administrativos, sua fundamentação foi voltada à análise do art. 21, VI, da LOMAN, que, em sua leitura, teria estabelecido a competência dos próprios tribunais para julgar originariamente mandado de segurança contra seus atos, independentemente da natureza.

Nessa linha, Sua Excelência rememorou o julgamento levado a efeito no AgR-MS no 3370/BA (Rel. Min. Eros Grau, DJ de 24/06/2008) e afastou a especialidade do Código Eleitoral diante da previsão da LOMAN. A ementa foi assim redigida:

ELEIÇÕES 2020. MANDADO DE SEGURANÇA. LEI ORGÂNICA DA MAGISTRATURA. COMPETÊNCIA DO RESPECTIVO TRIBUNAL REGIONAL PARA JULGAMENTO DE MANDADOS DE SEGURANÇA CONTRA SEUS ATOS, PRESIDENTES, CÂMARAS, TURMAS E SEÇÕES. DECLÍNIO DE COMPETÊNCIA.

1. Nos termos do inciso VI do art. 21 da Lei Orgânica da Magistratura Nacional, compete privativa e originariamente ao respectivo Tribunal Regional julgar os mandados de segurança contra seus atos, os dos respectivos Presidentes e os de suas Câmaras, Turmas ou Seções. 2. Incompetência absoluta do TRIBUNAL SUPERIOR ELEITORAL para julgamento originário de Mandado de Segurança contra ato administrativo, seja colegiado ou monocrático, dos Tribunais Regionais Eleitorais.

3. Mandado de segurança a que se declina da competência.

Naquela sessão, tive a oportunidade de ratificar meu entendimento, "colhido a partir da letra expressa do nosso Código Eleitoral, que tem uma referibilidade mais aguda com a matéria eleitoral do que a LOMAN - então me parece que aqui calharia à perfeição o espírito da especialização - e no seu art. 22, inciso I, prevê competência do Tribunal Superior Eleitoral para julgamento de mandado de segurança conta ato dos tribunais regionais". 
Ademais, expus que o precedente do Ministro Eros Grau mencionado no voto divergente tratou de matéria puramente administrativa impetração contra ato do TRF da 1ª Região que elegeu juiz federal para compor, como membro efetivo, o TRE/BA -, ao passo que no julgamento do qual participei o tema era eleitoral ou, quando não, decorrente de uma mescla entre matéria administrativa e eleitoral.

O julgamento recebeu um placar de votação bastante acirrado, com três votos pela competência do TSE e quatro pelo declínio, com a fixação de efeitos prospectivos, a partir do julgamento operado em 03/11/2020. Compondo a maioria, diante de ausência justificada do Ministro Luís Roberto Barroso, votou o Ministro Marco Aurélio.

Curiosamente, é de se notar que, na mesma sessão, ao julgar o AgR-MS nº 0601423-39/MT (Rel. Min. Mauro Campbell Marques, DJe de 30/11/2020), também a sempre ilustrada maioria considerou inaplicável a inflexão jurisprudencial supracitada, tendo em vista a existência, naqueles autos, de decisão definitiva do relator sorteado pela negativa de seguimento do mandado de segurança, a qual foi atacada por agravo interno, circunstâncias que justificariam a aplicação prospectiva da novel interpretação acerca da competência absoluta. No MS nº 0601612-17/PE, por outro lado, estava-se diante de referendo de liminar, tão somente.

O último capítulo atinente à celeuma sobreveio no julgamento do AgR-MS no 0601483-12/ES (Rel. Min. Sérgio Banhos, julgado em sessão eletrônica de 9 a 15/04/2021), em que o Diretório Municipal do Partido Rede Sustentabilidade questionou ato do Tribunal Regional Eleitoral do Espírito Santo (TRE/ES) que indeferiu seu pedido de veiculação de propaganda eleitoral televisiva no Município de Serra/ES. Na origem, o tribunal regional havia indeferido pedido administrativo para que fosse determinada a emissora de município diverso gerar e transmitir a propaganda eleitoral televisiva relativa às eleições municipais de Serra/ES. Com a composição titular do Plenário, o tema poderia ter sido debatido mais uma vez, não obstante assentou-se a perda superveniente do objeto do writ, tendo em vista o fim do pleito.

Ainda assim, no referido julgamento, o ministro relator havia assentado a incompetência absoluta do TSE para julgar o mandado de segurança, diante da compreensão firmada no MS no 0601612-17/PE, ocasião em que o Ministro Luís Roberto Barroso antecipou pedido de vista, prolatando seu voto na sessão de 24/11/2020 pela competência do TSE, o 
que reverteria o placar de quatro a três firmado no julgamento do processo anterior, do qual fui relator originário.

Como fundamento jurídico, o ministro vistor defendeu a higidez da regra de competência especial fixada no Código Eleitoral, que não atribuiu ao TSE o dever de julgar todos os mandados de segurança contra atos dos tribunais regionais, mas apenas aqueles que versassem sobre matéria eleitoral. Por isso, a LOMAN se aplicaria aos tribunais eleitorais normalmente, contudo, quando se tratasse de atos praticados pelos tribunais regionais no exercício de atribuições administrativas e regulamentares especializadas, a competência originária do mandado de segurança permaneceria sendo do TSE.

A título de argumentação pragmática, assentou também as particularidades da Justiça Eleitoral, inclusive quanto à exigência de celeridade, o que justificaria sua competência nessas situações, ainda que em contraste ao STJ ou ao STF, justamente para coibir, em grau originário, eventuais atos abusivos e ilegais dos tribunais regionais em matéria eleitoral.

Como dito, contudo, o encerramento do julgamento se deu por perda superveniente de objeto, após reajuste de voto do relator, o que impediu a fixação expressa e formal da posição atual do Colegiado sobre a matéria.

Importante igualmente rememorar o entendimento, de longa data, firmado no STF e que subsidiou também os debates travados recentemente no âmbito do TSE. No RE n⿳0 163727/RJ (Rel. Min. Ilmar Galvão, DJ de 20/04/2001), entendeu-se que o art. 22, I, e, do Código Eleitoral seria norma especial em face do regramento geral superveniente do art. 21, VI, da LOMAN, tendo como mote a maior eficácia e celeridade ao controle jurisdicional da atividade-fim, de cunho administrativo-eleitoral, dos tribunais regionais, conforme ementa que foi assim redigida:

EMENTA: ELEITORAL. PLEBISCITO CONVOCADO COM VISTAS À EMANCIPAÇÃO CONJUNTA DOS DISTRITOS DE ARMAÇÃO DE BÚZIOS E TAMOIOS, DO MUNICÍPIO DE CABO FRIO. CONSULTA RESPONDIDA AFIRMATIVAMENTE EM AMBOS OS DISTRITOS. AUSÊNCIA, TODAVIA, DE QUORUM DE COMPARECIMENTO NO SEGUNDO. RESULTADO CONSIDERADO ENGLOBADAMENTE PELO TRIBUNAL REGIONAL ELEITORAL, PARA FIM DE 
HOMOLOGAÇÃO. ACÓRDÃO DO TRIBUNAL SUPERIOR ELEITORAL QUE, DECIDINDO MANDADO DE SEGURANÇA IMPETRADO PELO MUNICÍPIO-MÃE, CONCLUIU EM SENTIDO CONTRÁRIO. ALEGADA INCOMPETÊNCIA DA REFERIDA CORTE PARA JULGAMENTO DE MANDADO DE SEGURANÇA CONTRA AS CORTES ELEITORAIS REGIONAIS, FACE À RESOLUÇÃO № 132/84, DO SENADO FEDERAL, SUSPENSIVA DA EXECUÇÃO DA EXPRESSÃO "OU MANDADO DE SEGURANÇA", QUE SE CONTINHA NO ART. 22, I, E, DO CÓDIGO ELEITORAL. ALEGADA OFENSA À NORMA DO ART. 52, X, DA CF, BEM COMO AOS PRINCÍPIOS DA INDEPENDÊNCIA DOS PODERES E DA COISA JULGADA. IRROGADA INCOMPATIBILIDADE DO ART. 3요 $₫ 4^{\circ}$, DA LEI COMPLEMENTAR ESTADUAL № 59/90 COM O ART. 14 E INC. I DA CF/88. Competência reconhecida ao TSE, para o feito, decorrente da interpretação acertadamente atribuída à Resolução no 132/84, do Senado Federal, para restringir o seu alcance à verdadeira dimensão da declaração de inconstitucionalidade do STF, no MS 20.409, que lhe deu causa, vale dizer, à hipótese de mandado de segurança contra ato, de natureza eleitoral, do Presidente da República, mantida a competência do TSE para as demais impetrações previstas no art. 22, I, e, do Código Eleitoral. Norma concebida com o propósito de dar maior eficácia e celeridade ao controle jurisdicional da atividade-fim, de cunho administrativo-eleitoral, das Cortes regionais, havendo subsistido, como lei especial, à lei geral do superveniente art. 21, VI, da LOMAN, considerada esta, no ponto, não como de caráter complementar, mas como norma ordinária, como preconizado no art. 137 da EC/69. Competência das Cortes eleitorais regionais tão-somente para os mandados de segurança contra atos inerentes à sua atividade-meio. $\mathrm{O}$ art. 3요 $\ 4^{\circ}$, da Lei Complementar $n^{2}$ 59/90, do Estado do Rio de Janeiro, ao exigir a observância do quorum de comparecimento em cada um dos distritos envolvidos num único processo de emancipação, não ofendeu o princípio da igualdade de voto, consagrado no art. 14 e inc. I da Carta Federal, que nada tem a ver com valor proporcional de cada voto, cuidando, ao revés, de simples aplicação, no campo do direito político, do princípio da igualdade de todos perante a lei, de molde a assegurar que o voto de cada cidadão tenha "o mesmo peso político e a mesma influência, qualquer que seja sua idade, suas qualidades, sua instrução e seu papel na sociedade." Recurso não conhecido. 
Como se infere da ementa e da leitura do inteiro teor do acórdão respectivo, o caso versou sobre mandado de segurança impetrado pelo $\mathrm{Mu}$ nicípio de Cabo Frio/RJ por meio do qual o TSE anulou consulta plebiscitária realizada entre os eleitores dos distritos de Tamoios e Armação dos Búzios, ao fundamento de não haver sido alcançado o quórum de comparecimento relativamente a cada um dos referidos distritos.

Dentre diversas questões agitadas na preliminar, o fundamento central para a admissão do mandado de segurança em circunstâncias tais girou em torno da necessária celeridade da matéria eleitoral, que imprime inquestionável conclusão acerca do cabimento do writ. Some-se a tal elemento a necessidade de fixação do juízo competente hierarquicamente superior para o conhecimento da ação, em razão da superlativa preocupação com a solução pronta e eficaz para a questão jurídica.

Outro ponto de debate travado à época foi o reflexo do julgamento do MS n² 20409/DF (Rel. Min. Djaci Falcão, DJ de 08/06/1984), em que, pela leitura do relatório e do voto do relator, considerou-se incidentalmente inconstitucional a competência do TSE para julgar mandado de segurança contra ato do presidente da República, porque tal atribuição é do próprio STF. Ocorre que, de maneira inadvertida, constou na conclusão do voto a declaração de inconstitucionalidade da locução "ou mandado de segurança” que consta no art. 22, I, e, do Código Eleitoral.

O Senado Federal, posteriormente, editou a Resolução nº 132, de 07/12/1984, para emprestar eficácia erga omnes ao pronunciamento, adicionando mais uma camada complicadora ao tema. De toda sorte, no julgamento do RE n⿳ 163727/RJ, toda a celeuma foi esclarecida, com a restrição do alcance da referida resolução à verdadeira dimensão da declaração de inconstitucionalidade operada no MS no $20409 / \mathrm{DF}$, que foi apenas a de preservar a competência do STF para julgamento de mandado de segurança contra ato do chefe do Executivo nacional.

\section{Conclusão}

De todo o apanhado a título de diagnóstico jurisprudencial, pode-se concluir que existiram balizas sólidas na fixação do entendimento até então plácido seguido no âmbito do TSE. O precedente firmado no STF no início de 2001 teve como mote a dinâmica eleitoral, com olhos não só às especificidades da competência da justiça especializada, mas também da 
necessidade de se conferir uma solução eficaz e, por isso, necessariamente célere às celeumas administrativo-eleitorais.

Nesse sentido, reputo correto o afastamento da competência do TSE para análise de mandado de segurança impetrado contra ato puramente administrativo emanado de tribunal regional. Nenhuma diferença existe nesse particular se analisada a mesma situação perante a justiça comum. Não se está, com isso, a taxar a desnecessidade de solução pronta e eficaz quanto a tais demandas, mas apenas a expressar que não há elemento diferenciador, sob o prisma eleitoral, para que se estabeleça regra diferenciada no pertinente ao cabimento e à competência para julgamento da ação constitucional.

Pretensões envolvendo nomeação e posse em cargo público, por exemplo, que são igualmente julgadas na justiça comum e na Justiça Eleitoral, advindas de atos puramente administrativos, devem seguir a mesma dinâmica ditada em ambas as searas. Nesse sentido, é possível a impetração do mandado de segurança, mas a competência para julgamento é do tribunal regional impetrado, com a possibilidade de análise da matéria pelo TSE em grau de recurso ordinário ${ }^{13}$.

Por outro lado, quanto a atos administrativo-eleitorais, não há como afastar a disposição que consta no art. 22, I, e, do Código Eleitoral, demonstrando-se como solução mais correta a atribuição de competência do próprio TSE para a análise de impetrações contra tribunais regionais.

Nesse enfoque da matéria, creio inexistir solução prática satisfatória em determinar ao próprio órgão ao qual é atribuída a pecha de possível prática de ato ilegal a competência para definir, em sede jurisdicional, o acerto da medida administrativo-eleitoral adotada.

Imaginem-se, com certeiro grau de empirismo, situações nas quais o tribunal regional edite resolução voltada ao rezoneamento eleitoral de determinado estado ${ }^{14}$ ou à renovação de eleição para a chefia do Executivo de forma indireta em razão da pandemia do coronavírus ${ }^{15}$. Em tais hipóteses, como em tantas outras, não há concretude em termos de eficácia ao se afastar a competência do TSE para julgamento de mandado de segurança.

\footnotetext{
${ }^{13}$ RMS no 0600337-21/PB, Rel. Min. Og Fernandes, DJe de 14/05/2019.

${ }^{14}$ AgR-MS nº 0604251-13/GO, Rel. Min. Tarcisio Vieira de Carvalho Neto, DJe de 12/03/2018. ${ }^{15}$ MS no 0600671-67/MT, Rel. Min. Edson Fachin, DJe de 02/09/2020.
} 
A celeridade ganha superlativa importância em demandas desse jaez, o que implica, necessariamente, atribuir a competência para análise da matéria diretamente ao Tribunal Superior. Nesse sentido, remanescendo apenas a via recursal ordinária para a devolução da matéria a órgão jurisdicional diverso, pouca ou nenhuma utilidade teria a impetração, isso passando ao largo do problema atinente à fixação jurisdicional da competência para análise de possível ilegalidade no mesmo órgão que expediu o comando eleitoral em sua faceta administrativa.

$\mathrm{Na}$ doutrina, o tema não passa despercebido, conforme preciso trecho que destaco:

Ressalte-se que, ao contrário da Justiça Comum, a Justiça Eleitoral, apresenta características próprias que faz com que a competência para o julgamento dos mandados de segurança contra decisões nela proferidas demande uma atenção mais detida. E isso ocorre especialmente porque a Justiça Eleitoral possui competência para prática de uma série de atos que não são considerados administrativos (atividade administrativa strictu sensu) e tampouco jurisdicionais (atividade jurisdicional). Referimo-nos à atividade judiciária (eleitoral) da Justiça Eleitoral, que não se confunde com as demais e que se reveste no lídimo exercício da Jurisdição Voluntária. Em relação a esses últimos é que há necessidade de tratamento mais específico, visto que a competência para julgamento do mandado de segurança sofrerá modificação. E isso porque o Código Eleitoral tem regra própria atribuindo competência originária ao TSE para julgar mandados de segurança, em matéria eleitoral, relativos a atos dos Tribunais Regionais (art. 22, I, "e"). Visando interpretar harmonicamente as regras aparentemente antagônicas - LOMAN atribuindo competência aos Regionais e CE conferindo competência ao TSE -, o Tribunal Superior utiliza-se da natureza do ato impugnado para fins de fixação de competência. Se o ato for de natureza jurisdicional (exercício da jurisdição eleitoral), a competência será fixada de acordo com a LOMAN, como referido acima, tendo competência o Tribunal Regional para o julgamento de atos praticados por juízes sob sua jurisdição. Também será de competência dos Tribunais Regionais os mandados de segurança impetrados quando o ato atacado é inerente a sua atividade-meio (atividade administrativa strictu sensu). Em matérias alusivas à economia interna (servidores, contratos, concursos públicos, licitações, etc.), portanto, eminentemente administrativa, mesmo que o ato seja emanado do próprio Tribunal Regional, será dele a competência ori- 
ginária para o julgamento do writ. [...] De outro lado, a competência será originária do TSE nas hipóteses em que o ato atacado é exercido no âmbito da atividade judiciária (em matéria eleitoral - não jurisdicional). Em tais hipóteses é que incide o art. 22, I, "e", do Código Eleitoral (JORGE; LIBERATO; RODRIGUES, 2016, p. 706-707).

Com efeito, torna-se descabida a tentativa de unificar o regime de competência atinente ao mandado de segurança impetrado na estrutura holística do Poder Judiciário. As Súmulas no 41 do STJ e no 624 do STF trataram, sem sombra de dúvida, com maestria, o tema no âmbito da jurisdição comum. Entende-se, aliás, que sua incidência não é de todo afastada na Justiça Eleitoral.

Como explicitado alhures, há atos administrativos em sentido estrito não relacionados ao procedimento eleitoral e que poderão ser questionados na via mandamental no próprio tribunal regional, bem como decisões jurisdicionais passíveis de recurso na via própria, contra os quais nem sequer caberá o mandado de segurança.

Por outro lado, é preciso conferir eficácia ao mandado de segurança quando impetrado contra ato administrativo-eleitoral, de modo que o art. 22, I, e, do Código Eleitoral deve ser prestigiado e lido nesse sentido e com esse alcance.

A impetração contra ato judicial somente cabe em hipótese excepcional, em que esteja evidenciada a situação teratológica e a possibilidade de dano irreparável ou de difícil reparação, ainda assim, nesses casos, a competência para o julgamento remanescerá no próprio tribunal (COÊLHO, 2016), em que pese a existência de precedentes bastante específicos nos quais se admitiu a competência do TSE, por exemplo, em impetração contra liminar de desembargador eleitoral que proibiu a divulgação de pesquisa eleitoral na véspera do pleito $^{16}$, ou mesmo em impetração contra tutela de urgência por intermédio da qual se sustou a diplomação de candidato eleito ${ }^{17}$.

Dito isso, é de se notar a existência de dupla bifurcação atinente à matéria. A primeira é aquela que divide a competência e o cabimento pela natureza do ato. Em se tratando de ato jurisdicional, a regra é o não cabimento, salvo se o caso envolver decisão teratológica contra a qual não

${ }^{16} \mathrm{AgR}-\mathrm{MS}$ n⿳0 3518/SP, Rel. Min. José Delgado, Rel. designado Min. Geraldo Grossi, PSESS em 30/09/2006.

${ }^{17}$ MS no $0601995-63 /$ SE, Rel. Min. Sergio Silveira Banhos, DJe de 25/06/2020. 
seja passível a interposição recursal. Nesse caso, admite-se o cabimento, de forma excepcional, porém com a fixação da competência no próprio TRE.

Em outro lado, tratando-se de decisões de natureza administrativa, o cabimento é tema menos turbulento, remanescendo questionamentos acerca da competência para o julgamento do writ. Nesse ponto, impõe-se nova bifurcação dentro da análise dos atos administrativos. Se o caso versar sobre ato administrativo em sentido estrito (puro) cabe ao próprio TRE julgar a impetração, ao passo que, se o ato detiver natureza administrativo-eleitoral, fixar-se-á a competência perante o TSE.

É essa a interpretação que guarda maior eficácia, em se tratando de procedimentos eleitorais, para fins de julgamento do mandado de segurança. Devolve-se a matéria ao TSE, de pronto, que definitivamente resolverá a questão no âmbito eleitoral, afastando do próprio órgão editor do ato administrativo-eleitoral a atribuição para aquilatar sua legalidade ou não.

Nesse sentido, guardo a compreensão de que o principal complicador seja a redação empregada no Código Eleitoral e a superveniência da LOMAN nesse particular. Veja-se que o art. 22, I, e, do Código Eleitoral mantém a competência do TSE para julgamento de mandado de segurança relativo a atos dos tribunais regionais em matéria eleitoral. Não há, como se vê, a divisão entre atos jurisdicionais ou administrativos e, dentre estes, aqueles de natureza puramente administrativa e os administrativo-eleitorais, sendo certo que, para fins de competência, apenas nessa fatia pequena é que a tarefa é relegada ao TSE na prática.

Com a redação superveniente do art. 21, VI, da LOMAN, no sentido de que compete ao próprio tribunal julgar, originariamente, os mandados de segurança contra seus atos - sem distinção -, compreende-se a origem das dissonâncias interpretativas acerca da matéria.

A solução, portanto, perpassa por uma singela alteração legislativa, que espancaria qualquer dúvida a respeito da competência para o julgamento da impetração, tanto em razão cronológica, por ser uma alteração superveniente à operada pela LOMAN, quanto pela melhor clareza terminológica a ser empregada no Código Eleitoral.

Com efeito, o art. 22, I, e, da Lei no 4.737/1965 deve ser alterado para explicitar que a competência do TSE para julgamento do mandado de segurança contra atos de tribunais regionais não se dá em "matéria eleitoral", mas em "matéria administrativo-eleitoral". 
Com isso, delimita-se de forma mais precisa a hipótese de cabimento compreendida como a mais harmônica com o sistema, em interpretação amparada nos precedentes do STF e do TSE de longa data acerca da matéria.

Afasta-se, de pronto, a competência do TSE para julgamento de impetrações contra atos de índole jurisdicional. Delimita-se, ao mesmo tempo, que, em se tratando de atos de natureza administrativa, apenas aquele que verse sobre matéria eleitoral será passível de impetração perante o TSE, repudiando-se, portanto, a competência do TSE para análise de impetrações contra atos administrativos puros, atribuição do próprio tribunal regional.

\section{Referências}

BRASIL. Superior Tribunal de Justiça. Súmula n 41: O Superior Tribunal de Justiça não tem competência para processar e julgar, originariamente, mandado de segurança contra ato de outros Tribunais ou dos respectivos órgãos. Diário da Justiça, Brasília, DF, 20 maio 1992.

BRASIL. Supremo Tribunal Federal. Recurso Extraordinário 163727 - Rio de Janeiro. ELEITORAL. PLEBISCITO CONVOCADO COM VISTAS À EMANCIPAÇÃO CONJUNTA DOS DISTRITOS DE ARMAÇÃO DE BÚZIOS E TAMOIOS, DO MUNICÍPIO DE CABO FRIO. CONSULTA RESPONDIDA AFIRMATIVAMENTE EM AMBOS OS DISTRITOS. [...] IRROGADA INCOMPATIBILIDADE DO ART. 3ㅇ, \ 4º, DA LEI COMPLEMENTAR ESTADUAL № 59/90 COM O ART. 14 E INC. I DA CF/88. Relator: ILMAR GALVÃO, Data de Julgamento: 07/04/1994, Tribunal Pleno, Data de Publicação: Diário da Justiça, Brasília, DF, 20 abr. 2001.

BRASIL. Supremo Tribunal Federal. Mandado de Segurança 20409 - Distrito Federal. MANDADO DE SEGURANÇA. COMPETÊNCIA. COMPETÊNCIA ORIGINÁRIA DO SUPREMO TRIBUNAL PARA PROCESSAR E JULGAR MANDADO DE SEGURANÇA CONTRA ATOS DO PRESIDENTE DA REPÚBLICA. [...] MANDADO DE SEGURANÇA QUE SE JULGA PREJUDICADO. Relator: DJACI FALCAO, Data de Julgamento: 31/08/1983, Tribunal Pleno, Data de Publicação: Diário da Justiça, Brasília, DF, 8 jun. 1984. 
BRASIL. Supremo Tribunal Federal. Súmula nº 624: Não compete ao Supremo Tribunal Federal conhecer originariamente de mandado de segurança contra atos de outros tribunais. Diário da Justiça, Brasília, DF, 13 out. 2003.

BRASIL. Tribunal Superior Eleitoral. Agravo Regimental em Mandado de Segurança 0600072-19 - Rondônia. DIREITO ADMINISTRATIVO. AGRAVO INTERNO EM RECURSO ORDINÁRIO. MANDADO DE SEGURANÇA. REMOÇÃO DE SERVIDORA PARA ACOMPANHAR COMPANHEIRO. INTERESSE DA ADMINISTRAÇÃO. COABITAÇÃO PRÉVIA. DESNECESSIDADE. PRESERVAÇÃO DA UNIDADE FAMILIAR. PRECEDENTES. ALEGADA INTEMPESTIVIDADE DO RECURSO. INOVAÇÃO RECURSAL INADMITIDA PELA JURISPRUDÊNCIA DESTA CORTE. AUSÊNCIA DE ARGUMENTOS SUFICIENTES PARA MODIFICAR A CONCLUSÃO EXPOSTA NA DECISÃO AGRAVADA. NEGADO PROVIMENTO AO AGRAVO INTERNO. Relator: Ministro Mauro Campbell Marques. Agravante: União. SESSÃO DE 18.3.2021. Diário da Justiça eletrônico, 6 abr. 2021.

BRASIL. Tribunal Superior Eleitoral. Agravo Regimental em Mandado de Segurança 0600345-10 - Rio Grande do Sul. AGRAVO INTERNO. MANDADO DE SEGURANÇA. DECISÃO MONOCRÁTICA DE MEMBRO DE TRE. APLICABILIDADE. SÚMULA 34/TSE. MANDAMUS INCABÍVEL. NEGATIVA DE PROVIMENTO. Relator: Ministro Luis Felipe Salomão. Agravante: Partido Progressista (PP) - Estadual. SESSÃO DE 13.8.2020. Diário da Justiça eletrônico, 23 set. 2020.

BRASIL. Tribunal Superior Eleitoral. Agravo Regimental em Mandado de Segurança 0600418-79 - Amazonas. ELEIÇÕES 2016. AGRAVO REGIMENTAL. MANDADO DE SEGURANÇA. IMPETRAÇÃO. ATO COMBATIDO. DECISÃO CONCESSIVA DE EFEITO SUSPENSIVO. LAVRA DE MINISTRO RELATOR DO RECURSO CORRESPONDENTE NO TRIBUNAL SUPERIOR ELEITORAL. IMPUGNAÇÃO NA VIA DO MANDAMUS. IMPOSSIBILIDADE. INCIDÊNCIA DA SÚMULA N. 22/TSE. TERATOLOGIA AUSENTE. FLAGRANTE INTENTO DE UTILIZAÇÃO DO Writ COMO SUCEDÂNEO DA VIA RECURSAL ADEQUADA À ESPÉCIE. DESPROVIMENTO. Relator: Ministro Tarcisio Vieira de Carvalho Neto. Agravante: Avante (AVANTE) - Municipal. SESSÃO DE 1․7.2020. Diário da Justiça eletrônico, 10 ago. 2020. 
BRASIL. Tribunal Superior Eleitoral. Agravo Regimental em Mandado de Segurança 0601345-45 - Espírito Santo. AGRAVO INTERNO. MANDADO DE SEGURANÇA. FILIAÇÃO PARTIDÁRIA. SUSPENSÃO CAUTELAR. COMISSÃO DE ÉTICA. PREVISÃO NO ESTATUTO DA GREI. LIMINAR INDEFERIDA. PARECER MINISTERIAL. DENEGAÇÃO DA ORDEM. SUPERVENIÊNCIA. ELEIÇÕES 2020. AUSÊNCIA. REFLEXOS. PROCESSO ELEITORAL. PREJUDICIALIDADE. NEGATIVA DE PROVIMENTO. Relator: Ministro Luis Felipe Salomão. Agravante: Marcelino Ayub Fraga. Agravado: Luiz Felipe Baleia Tenuto Rossi. SESSÃO DE 25/03/2021. Diário da Justiça eletrônico, 22 abr. 2021.

BRASIL. Tribunal Superior Eleitoral. Agravo Regimental em Mandado de Segurança 0601423-39 - Mato Grosso. ELEIÇÕES 2018. AGRAVO INTERNO EM MANDADO DE SEGURANÇA CÍVEL. ANOTAÇÃO NO CADASTRO ELEITORAL DO CÓDIGO ASE 540, RELATIVO AO COMETIMENTO DE ILÍCITO ELEITORAL. BANCO DE DADOS DE CARÁTER CONSULTIVO. EFEITO NÃO OBSTADO PELA NORMA DO ART. 257, \ 2², DO CE. DECISÃO MANTIDA POR SEUS PRÓPRIOS FUNDAMENTOS. AGRAVO DESPROVIDO. Relator: Ministro Mauro Campbell Marques. Agravante: José Pedro Gonçalves Taques. SESSÃO DE 03/11/2020. Diário da Justiça eletrônico, 30 nov. 2020.

BRASIL. Tribunal Superior Eleitoral. Agravo Regimental em Mandado de Segurança 0601483-12 - Espírito Santo. Rel. Min. Sérgio Banhos, julgado em sessão eletrônica de 9 a 15/04/2021. Pendente de publicação.

BRASIL. Tribunal Superior Eleitoral. Agravo Regimental em Mandado de Segurança 0604251-13 - Goiás. AGRAVO REGIMENTAL. MANDADO DE SEGURANÇA. RESOLUÇÃO. TRIBUNAL REGIONAL ELEITORAL. REZONEAMENTO. OBEDIÊNCIA À RES.- TSE N. 23.520/2017. HOMOLOGAÇÃO PELO TRIBUNAL SUPERIOR ELEITORAL. REQUISITOS LEGAIS E REGULAMENTARES PREENCHIDOS. ILEGALIDADE E TERATOLOGIA NÃO CONFIGURADAS. AUSÊNCIA DE DIREITO LÍQUIDO E CERTO. PRÉVIA INTIMAÇÃO DE PAUTA. SESSÃO ADMINISTRATIVA DO TRE. AUSÊNCIA DE PREVISÃO NORMATIVA. DESPROVIMENTO. Relator: Ministro Tarcisio Vieira de Carvalho Neto. Agravante: Associação dos Magistrados do Estado de Goiás. Autoridade Coatora: Presidente do Tribunal Regional Eleitoral de Goiás. SESSÃO DE 08/02/2018. Diário da Justiça eletrônico, 12 mar. 2018. 
BRASIL. Tribunal Superior Eleitoral. Agravo Regimental em Mandado de Segurança 311-90 - Bahia. RECURSO EM MANDADO DE SEGURANÇA. DECISÃO. PRESIDÊNCIA DA CORTE DE ORIGEM. DESPROVIMENTO. RECURSO ADMINISTRATIVO. CONCURSO DE REMOÇÃO. CRITÉRIOS DE PONTUAÇÃO. CONTAGEM DE TEMPO DE SERVIÇO. Relator: Ministro Henrique Neves da Silva. Agravante: Paulo César Lopes Guerra. SESSÃO DE 18/09/2014. Diário da Justiça eletrônico, 26 set. 2014.

BRASIL. Tribunal Superior Eleitoral. Agravo Regimental em Mandado de Segurança 3370 - Bahia. AGRAVO REGIMENTAL. MANDADO DE SEGURANÇA. COMPETÊNCIA. EXAME. TRF 1a REGIÃO. DECLINAÇÃO. LOMAN, ART. 21, INCISO VI. CF, ART. 108, INCISO I, ALÍNEA C. Relator: Ministro Eros Grau. Agravante: José Henrique Guaracy Rebelo. Agravado: Tribunal Regional Federal da 1를 Região. Agravado: Presidente do Tribunal Regional Federal da 1를 Região. SESSÃO DE 03/06/2008. Diário da Justiça eletrônico, 24 jun. 2008.

BRASIL. Tribunal Superior Eleitoral. Agravo Regimental em Mandado de Segurança 3518 - São Paulo. MANDADO DE SEGURANÇA. SITUAÇÃO EXCEPCIONAL. PESQUISA. PROIBIÇÃO DE DIVULGAÇÃO NA VÉSPERA DO PLEITO ELEITORAL. LIMINAR. INDEFERIMENTO. AGRAVO REGIMENTAL. Relator originário: Ministro José Delgado. Redator para o acórdão: Ministro Gerardo Grossi. Agravante: IBOPE - Opinião Pública Ltda. PSESS DE 30/09/2006.

BRASIL. Tribunal Superior Eleitoral. Agravo Regimental em Mandado de Segurança 602-02 - Espírito Santo. AGRAVO REGIMENTAL. MANDADO DE SEGURANÇA. RECURSO ESPECIAL ELEITORAL INEXISTENTE. EMBARGOS DE DECLARAÇÃO OPOSTOS PERANTE TRIBUNAL REGIONAL. PEDIDO DE EFEITO SUSPENSIVO. INCOMPETÊNCIA DO TSE. NÃO PROVIMENTO. Relator: Ministro Aldir Passarinho Junior. Agravantes: Estevam Antônio Fiório e outro. Órgão coator: Tribunal Regional Eleitoral do Espírito Santo. SESSÃO DE 02/06/2011. Diário da Justiça eletrônico, 14 set. 2011. 
BRASIL. Tribunal Superior Eleitoral. Agravo Regimental em Recurso Especial Eleitoral 0600248-42 - Ceará. PSESS de 04/12/2020. ELEIÇÕES 2020. AGRAVO REGIMENTAL. AGRAVO EM RECURSO ESPECIAL. NEGATIVA DE SEGUIMENTO. MANDADO DE SEGURANÇA. ATO ILEGAL. DESTITUIÇÃO DE COMISSÃO PROVISÓRIA MUNICIPAL. INOBSERVÂNCIA DOS PRINCÍPIOS DO CONTRADITÓRIO E DA AMPLA DEFESA. DESPROVIMENTO. Relator: Ministro Sérgio Banhos. Agravante: Partido Social Cristão (PSC) - Estadual. Agravados: Henrique Correia Lopes e outro. PSESS DE 04/12/2020.

BRASIL. Tribunal Superior Eleitoral. Mandado de Segurança 0600671-67 - Mato Grosso. MANDADO DE SEGURANÇA. ELEIÇÕES SUPLEMENTARES. PANDEMIA DE COVID-19. ELEIÇÕES INDIRETAS. VACÂNCIA A MAIS DE UM ANO DO TÉRMINO DO MANDATO. VACÂNCIA ELEITORAL. CASSAÇÃO DO DIPLOMA PELO TRIBUNAL REGIONAL ELEITORAL EM 2019. PRINCÍPIO DA IMEDIATICIDADE DO SUFRÁGIO. OBSERVÂNCIA AO DISPOSTO NO ART. 224, \ 4 , II, DO CE. LIMINAR DEFERIDA. INTIMAÇÃO DO IMPETRANTE PARA REGULARIZAÇÃO DO POLO PASSIVO. VÍCIO FORMAL. EMBARGOS DECLARATÓRIOS. PROVIMENTO PARA SANAR ERRO FORMAL. LIMINAR DEFERIDA. JUÍZO PERFUNCTÓRIO. SUBMISSÃO AO PLENÁRIO. SESSÃO DE JULGAMENTO VIRTUAL. MEDIDA LIMINAR REFERENDADA. Relator: Ministro Edson Fachin Impetrante: Partido da República (PR) - Municipal. Impetrado: Presidente do Tribunal Regional Eleitoral de Mato Grosso. SESSÃO DE 20/08/2020. Diário da Justiça eletrônico, 2 set. 2020.

BRASIL. Tribunal Superior Eleitoral. Mandado de Segurança 0601995-63 - Sergipe. MANDADO DE SEGURANÇA. ATO JUDICIAL. TUTELA PROVISÓRIA DE URGÊNCIA. NEGAÇÃO DO DIPLOMA. MANIFESTA ILEGALIDADE. CONCESSÃO. Relator: Ministro Sérgio Banhos. Impetrante: José Valdevan de Jesus Santos. Autoridade coatora: Presidente do Tribunal Regional Eleitoral de Sergipe. SESSÃO DE 26/09/2019. Diário da Justiça eletrônico, 25 jun. 2020. 
BRASIL. Tribunal Superior Eleitoral. Mandado de Segurança Cível 0601044 98 - Mato Grosso. ELEIÇÕES 2020. MANDADO DE SEGURANÇA. LIMINAR CONCEDIDA. AGRAVOS REGIMENTAIS. PRELIMINAR. LITISCONSÓRCIO PASSIVO. REJEIÇÃO. MÉRITO. DESIGNAÇÃO DE PRIMEIRA ELEIÇÃO PARA O MUNICÍPIO DE BOA ESPERANÇA DO NORTE EM 2020. AFERIÇÃO DOS LIMITES DA COMPETÊNCIA DO TRIBUNAL REGIONAL ELEITORAL DE MATO GROSSO. IMPOSSIBILIDADE DE REVERTER DECISÃO DO TRIBUNAL DE JUSTIÇA MATO-GROSSENSE JÁ SOB OS EFEITOS DA COISA JULGADA. INCOMPETÊNCIA ABSOLUTA. CONFIRMAÇÃO DA LIMINAR CONCEDIDA. VÍCIO DE MANIFESTA ILEGALIDADE NO ATO IMPUGNADO. CONCESSÃO DA SEGURANÇA. AGRAVOS REGIMENTAIS AOS QUAIS SE NEGA PROVIMENTO QUANTO À PRELIMINAR E, NO MÉRITO JULGA-SE PREJUDICADOS. Relator: Ministro Edson Fachin. Agravante: Dilmar Dal Bosco. Agravante: Município de Sorriso. SESSÃO DE 20/10/2020. Diário da Justiça eletrônico, 2 dez. 2020 .

BRASIL. Tribunal Superior Eleitoral. Processo Administrativo 323-45 - Distrito Federal. ATUALIZA A JURISPRUDÊNCIA SUMULADA DO TSE. Relator: Ministro Dias Toffoli. Interessado: Tribunal Superior Eleitoral. SESSÃO DE 10/05/2016. Diário da Justiça eletrônico, 24, 27 e 28 jun. 2016.

BRASIL. Tribunal Superior Eleitoral. Recurso Ordinário em Mandado de Segurança 0600337-21 - Paraíba. RECURSO EM MANDADO DE SEGURANÇA. CONCURSO PÚBLICO. LEI № 12.990 /2014. ALEGADA PRETERIÇÃO NA ORDEM DE NOMEAÇÃO. ALEGAÇÃO DE VIOLAÇÃO AOS CRITÉRIOS DA ALTERNÂNCIA E DA PROPORCIONALIDADE. NÃO OCORRÊNCIA. NEGADO PROVIMENTO. Relator: Ministro Og Fernandes. Recorrente: Carlos Trajano de Oliveira. Recorrido: Leonel Marques de Luna Freire. Recorrida: União. SESSÃO DE 14/05/2019. Diário da Justiça eletrônico, 14 maio 2019.

BRASIL. Tribunal Superior Eleitoral. Recurso Ordinário em Mandado de Segurança 0603474-42 - Goiás. Rel. Min. Tarcisio Vieira de Carvalho Neto. Diário da Justiça eletrônico, 12 ago. 2020. Pendente de publicação.

COÊLHO, Marcus Vinicius Furtado. Direito eleitoral, processual eleitoral, penal eleitoral. 4. ed. Belo Horizonte: Fórum, 2016.

GOMES, José Jairo. Direito eleitoral. 12. ed. São Paulo: Atlas, 2016. 
JORGE, Flávio Cheim; LIBERATO, Ludgero; RODRIGUES, Marcelo Abelha. Curso de direito eleitoral. Salvador: JusPodivm, 2016.

VELLOSO, Carlos Mário da Silva; AGRA, Walber de Moura. Elementos de direito eleitoral. 4. ed. São Paulo: Saraiva, 2014.

Tarcisio Vieira de Carvalho Neto - Pós-doutor em Democracia e Direitos Humanos (Direito, Política, História e Comunicação) pelo Ius Gentium Conimbrigae, da Faculdade de Direito da Universidade de Coimbra. Doutor e mestre em Direito do Estado pela Faculdade de Direito da Universidade de São Paulo (FD/USP). Ministro do Tribunal Superior Eleitoral. Professor adjunto da Faculdade de Direito da Universidade de Brasília (FD/ UnB). Subprocurador-geral do Distrito Federal. Advogado. E-mail: tarcisio@gvc.adv.br. ORCID: https://orcid.org/0000-0001-8930-2838. 
